\title{
DEFENSA AL DERECHO FUNDAMENTAL À LA REPRODUCCIÓN - SENTENCIA T-627 DE 2012 DE LA CORTE CONSTITUCIONAL DE COLOMBIA ${ }^{1}$
}

Defense of the fundamental reproductive right - judgment T-627 of 2012 of the Constitutional Court of Colombia

${ }^{1}$ Universidad ISALUD. Buenos Aires, Argentina.

${ }^{2}$ Universidad de Buenos Aires. Buenos Aires, Argentina.

Correspondência: Claudia Viviana Madies. E-mail: madies.claudia@gmail.com.

Recebido em: 15/10/2013. Aprovado em: 12/11/2013

\footnotetext{
${ }^{1}$ Sentencia de la Corte Constitucional de Colombia No T-627/12. Referencia: expediente T-3.331.859. Acción de tutela instaurada por Mónica del Pilar Roa López y otras 1279 mujeres. Sala integrada por los Magistrados María Victoria Calle Correa, Luis Ernesto Vargas Silva y Humberto Antonio Sierra Porto. Disponible en: <www.corteconstitucional.gov.co/?a1u>. Consultada en: 1 de octubre de 2013.
} 


\section{RESUMEN}

El objeto de este artículo es comentar y reflexionar jurídicamente sobre la Sentencia T-627/12 de la Sala Octava de Revisión de la Corte Constitucional de Colombia. Interesa este pronunciamiento que reconoce el derecho a la información como parte integrante de los derechos reproductivos de las mujeres y hombres colombianos y el innovador abordaje judicial desde la perspectiva de la responsabilidad de los funcionarios involucrados, en el contexto de una progresiva línea jurisprudencial con enfoque de tutela efectiva de derechos.

\section{Palabras claves}

Constitucional; Diseminación de Información; Derechos de la Mujer; Derechos Reproductivos; Salud.

\section{ABSTRACT}

This article aims to discuss the judgment T-627/12 of the Constitutional Court of Colombia. This judgment is important because it recognizes the right to be informed as part of the reproductive right of Colombian women and men. This sentence also counts with an innovative judicial approach from the perspective of the responsibility of the officials involved, in the context of a progressive jurisprudentially line focusing in the effective legal protection.

\section{Keywords}

Constitutional; Health; Information; Reproductive Rights; Women’s Rights. 


\section{Introducción y antecedentes}

El objeto de este artículo es realizar un comentario jurídico y reflexionar sobre las cuestiones vinculadas al derecho de la salud, como derecho humano fundamental, concebido en toda su riqueza, suscitado con la decisión de la Corte Constitucional de Colombia del 10 de agosto de 2012.

Se trata de la Sentencia T-627/12 de la Sala Octava de Revisión de la Corte Constitucional dictada en Colombia, en el expediente T-3.331.859, instada por la Acción de tutela instaurada por 1.280 mujeres en contra de medidas adoptadas por el Procurador General de la Nación, Alejandro Ordóñez Maldonado, y otras autoridades estatales.

El tema central en la interpretación constitucional lo constituyen las manifestaciones de los derechos reproductivos de las mujeres, uno de los cuales es el derecho a la información en materia reproductiva. Junto a éste derecho están involucrados los derechos a: la autonomía reproductiva, la interrupción voluntaria del embarazo (IVE), el acceso a los servicios de salud reproductiva, la educación y la información sobre métodos anticonceptivos y su libre elección y acceso.

La decisión emana de la Corte Constitucional, creada por la actual Constitución Política colombiana, reformada en el año 1991. La Corte pertenece a la rama judicial del Gobierno federal y debe guardar la integridad y supremacía de la Carta Magna Colombiana. Según el artículo 241 de dicha Constitución, decide sobre las demandas de constitucionalidad que promuevan los ciudadanos contra las leyes, los decretos con fuerza de ley dictados por el Gobierno y los actos legislativos reformatorios de la Constitución. Los fallos que la Corte dicta en ejercicio del control jurisdiccional hacen cosa juzgada constitucional. Ninguna autoridad podrá reproducir el contenido material del acto jurídico declarado inexequible por razones de fondo, mientras subsistan en la Carta las disposiciones que sirvieron para hacer la confrontación entre la norma ordinaria y la Constitución (artículo 243 de la Constitución de Colombia).

Entre las funciones del Tribunal, ejercidas en el caso comentado (de Revisión, conformada por salas) está el revisar, en la forma que determine la ley, las decisiones judiciales relacionadas con la acción de tutela de los derechos constitucionales. En precedentes, como en el fallo T-355 de 2006², la misma Corte con efecto erga omnes, emitió órdenes estructurales en materia de salud reproductiva, sobre la IVE, eliminando del ordenamiento colombiano la prohibición en términos absolutos del aborto. A partir de ese fallo surgió en Colombia un verdadero derecho a la IVE en cabeza de las mujeres que se encuentran incursas en las hipótesis despenalizadas, al declarar el tribunal inconstitucional e inexequibles varias normas penales, habilitándolo en tres circunstancias (riesgo para la vida o salud de la mujer, delito de violación o mediante

${ }^{2}$ Sentencia T-355 de 2006 de la Corte Constitucional de Colombia del 10 de mayo de 2006. 
inseminación sin su consentimiento e inviabilidad debida a la malformación del feto, vg., anencefalia). En este caso, el tribunal consideró que las normas impugnadas coartaban irrazonablemente el ejercicio de los derechos humanos fundamentales de la mujer (a la salud, vida, la integridad de su propio cuerpo y la autonomía reproductiva).

Desde su creación la Corte, tomó un creciente protagonismo que no se ha limitado a la muy importante - más no suficiente - tutela de los derechos, sino que, al menos en lo que hace al derecho de la salud y otros derechos sociales y para alguna doctrina: "ha defendido una concepción de la sociedad colombiana marcadamente diferente a la visión que procura plasmar la rama ejecutiva a través de las políticas económicas y sociales, así como la elaboración democrática de políticas”3.

Según señalan los autores Yamin, Parra Vera y Gianellalos actos y comunicaciones dictados y emitidos por un nuevo Procurador General de la Nación en el año 2010 y sus auxiliares se constituyeron en un obstáculo legal a la aplicación del fallo T-355/06 por parte de distintas instituciones y funcionarios involucrados. Estos autores indican que - previo al pronunciamiento comentado - la Corte necesariamente, al depender "de la cooperación de actores e instituciones políticas en lo que atañe a la implementación ha limitado, en la práctica, los efectos de esas decisiones en los derechos de la salud de la mujer"4. De aquí la importancia de la Sentencia T-627/12 que remueve estos obstáculos.

Para la correcta interpretación de la Sentencia en comentario cabe estudiarla en el contexto de las decisiones de la Corte Constitucional sentadas en la T-585/10 , doctrina reiterada en la T-841/11 ${ }^{6}$, restringidas a las hipótesis de interrupción del embarazo establecidas en la sentencia C-355/067, como también lo resuelto en el Auto 038 del año 2012 (de la sala en pleno) ${ }^{8}$ que desestimó el planteo de nulidad de la sentencia T-585/10.

\section{Derechos a la salud reproductiva y a la información}

Para iniciar el análisis de la Sentencia T-627/12 conviene considerar si como pretendieron las demandantes los funcionarios del ministerio público demandados afectaron solo su derecho a la información o los derechos reproductivos del conjunto de la población colombiana, a partir del incumpliendo de sus poder deber de facilitar la conformación de una opinión pública informada, como presupuesto para la participación ciudadana en la toma de decisiones que los afectan, por ser propio de las democracias contemporáneas.

\footnotetext{
${ }^{3}$ YAMIN, Alicia Ely; PARRA-VERA, Oscar; GIANELLA; Camila. Colombia: la protección judicial del derecho a la salud. ¿Una promesa difícil de cumplir? Con cita de Uprimny y García Villegas. In: YAMIN, Alicia Ely; GLOPPEN, Siri (coord.) La lucha por los derechos a de la salud. Ed. Siglo XXI, 2013, p. 127-157.

${ }^{4}$ Id. Ibid.

${ }^{5}$ Sentencia T-585/10 de la Corte Constitucional de Colombia del 22 de julio de 2010.

${ }^{6}$ Sentencia T-841/11 de la Corte Constitucional de Colombia del 3 de noviembre de 2011.

${ }^{7}$ Sentencia C-355/06. op. cit.

${ }^{8}$ Auto 038 del año 2012 de la Corte Constitucional de Colombia del 28 de febrero del 2012.
} 
En nuestra opinión, prevalece la segunda opción por haberse afectado el derecho a la información genérico de raigambre constitucional, y de acceso a la misma, el que se inscribe entre "los derechos reproductivos de las mujeres". El Tribunal ubica el derecho a ser informado o a "recibir información" como parte de un "interés colectivo reflejado en el derecho de la comunidad a ser informada" de manera "veraz e imparcial". Desde este enfoque se comprende la aplicación general de esta doctrina, que establece un "deber correlativo de los emisores de la información", a la actividad estatal y a la de los funcionarios que se desempeñan en sus órganos.

Cuando está involucrada la actividad de comunicación de altos funcionarios públicos con la ciudadanía, en ejercicio del poder-deber correlativo, éste se halla sujeto -según doctrina del Tribunal - a los límites que la jurisprudencia constitucional e interamericana han fijado. Es entonces, el ejercicio de esta potestad-deber (cuyo contenido concreto en el caso son las instrucciones a otros funcionarios y opiniones vertidas a los medios de comunicación, que expresan la interpretación de sentencias y normas) el que ha tenido la idoneidad de afectar "los derechos reproductivos de las mujeres", "uno de los cuales -mas no el único- es el derecho a la información en materia reproductiva" Por ende, no duda el Tribunal en que tal potestad deber involucra también al procurador y sus auxiliares demandados, como parte del Ministerio Público.

Por otra parte, previo a este caso, el proyecto Género y Justicia de Women's Link Worldwide, se sirvió del litigio estratégico para lograr la inconstitucionalidad de determinados artículos del Código Penal colombiano, que dio lugar a la sentencia Corte Constitucional de Colombia. Sentencia C-355/06 ${ }^{11}$. Aquel fallo hizo notar que el cambio político de un Estado Liberal de Derecho - fundado en la soberanía nacional y en el principio de legalidad - a un Estado Social de Derecho - que entre sus fines esenciales tiene la garantía de efectividad de principios, derechos y deberes constitucionales - presupone la renuncia a teorías absolutas de la autonomía legislativa en materia penal. Plantea la necesidad de recurrir a un juicio de proporcionalidad para decidir en qué circunstancias el legislador penal, con el propósito de proteger la vida del nasciturus termina afectando de manera desproporcionada los derechos de la mujer y transgrediendo los límites dentro de los cuales puede ejercer su potestad legislativa, por lo cual termina declarando exequibles ciertos artículos del código penal ${ }^{12}$. Ese fallo, proyecta una doctrina jurisprudencial nueva sobre

\footnotetext{
${ }^{9}$ Sentencia T-552/95 del año 1995, 27 de noviembre. Cursiva no original.

${ }^{10}$ Acápite 32 del fallo - Los derechos reproductivos en la Constitución de 1991 y en el bloque de constitucionalidad. Reiteración de jurisprudencia. Doctrina sentada en la sentencia de la Corte en C-355 de 2006.

${ }^{11}$ Acápite 32 de Sentencia T627/12 (op. cit.)

${ }^{12}$ SALGADO ÁLVAREZ, Judith. Análisis de la sentencia de la Corte Constitucional de Colombia sobre la despenalización parcial del aborto. FORO Revista de Derecho, Quito, n. 9, 2008.
} 
el contenido de los derechos reproductivos de las mujeres de los que mana el derecho a la información en materia reproductiva, ya no son solo prerrogativas individuales, sino que imponen contenidos progresivos a los llamados "poderes-deberes" del Estado que alcanzan a sus funcionarios.

La Corte Colombiana se centra en las responsabilidades de los funcionarios del Estado Colombiano y haciéndolo dota a su pronunciamiento de un efecto erga hommes que trasciende a las pretensiones de las propias presentantes, restándoles discrecionalidad en el ejercicio de sus funciones al Procurador y sus auxiliares, en tanto éstas emanen del marco legal del texto legal debatido democráticamente.

No obstante, hay una escasa referencia en este exegético pronunciamiento judicial, a cómo en las instituciones democráticas dialoga el poder judicial con los otros poderes del estado, y a cómo se justifica que el máximo tribunal refleje en sus pronunciamientos los valores que prevalecen en la sociedad colombiana, ponderando los espacios de participación democrática. Si bien no puede sostenerse que fue soslayado este aspecto en el decisorio comentado, no consideró su texto de qué modo todas las instituciones del estado democrático de derecho colombiano avanzan en la efectiva instrumentación de los derechos sexuales y reproductivos de las mujeres y hombres de ese país.

Según cierta doctrina colombiana se están produciendo cambios constitucionales implícitos y prevalece una constitución no escrita vía el bloque de constitucionalidad que hace parte de la Constitución a los Tratados Internacionales de Derechos Humanos ${ }^{13}$. Esa doctrina discute si la falta de legitimidad democrática puede serle opuesta al máximo tribunal, que no es elegido por el voto popular para decidir tan trascendentes cuestiones, cuando se carece de marco legal, sea desde el punto de vista procedimental como sustancial. Si bien el primero es discutible, no lo es tanto en el segundo cuando la Corte se pronuncia en defensa de los derechos de las minorías.

En respuesta a quienes alegan que en el caso de los derechos reproductivos la Corte sustituyó el artículo 11 de la Constitución Colombiana, extralimitándose en sus funciones al dictar la sentencia 355-06, otra parte de la doctrina indica que la Corte acordó en la sentencia C-486/93 al término Ley un equivalente a ordenamiento jurídico, que como principal fuente de derecho incluye a la propia constitución. Esta doctrina indica que la sentencia C-551/03 de la Corte señaló que el Congreso tiene competencia para reformar la Constitución pero no para sustituirla, derogarla o subvertirla y por ende, la Corte en su control de constitucionalidad tiene que mantener la supremacía de la constitución y defender la voluntad del pueblo en la

${ }^{13}$ BENITEZ R., Vicente F. Legitimidad democrática y constitucional de las modificaciones implícitas de la Constitución por parte de la jurisprudencia de constitucional de Colombia. Universitas, n. 122, p. 303-334, 2011. 
medida en que no puede sostenerse que un grupo de congresistas tiene el mismo poder constituyente que el pueblo.

Al ponderar si estos pronunciamientos, como sostiene esa última doctrina, derivan de la inactividad del legislador para la defensa de estas minorías o en la falta de participación de esos grupos en los debates parlamentarios, surge el Tribunal como árbitro para destrabar el juego político si las minorías fueron indebidamente coartadas.

\section{Reflexiones finales}

El decisorio en análisis, al enmarcarse en una línea jurisprudencial de progresivo reconocimiento de derechos reproductivos tiene alta relevancia para la interpretación de posteriores intervenciones de los otros jueces del país en otros casos. Revierte los decisorios de las instancias previas, fortalece el cumplimiento de la sentencia C-355/06, reitera la obligación del Estado de garantizar a todas las mujeres sus derechos sexuales y reproductivos a través de los servicios de salud, incluso el acceso a la IVE en los casos ya establecidos. Además, la Corte se pronuncia sobre la obligación y el deber de los funcionarios públicos en materia de salud sexual y reproductiva de facilitar información clara, fidedigna, confiable y oportuna a las mujeres sobre sus derechos. Aclara que los funcionarios públicos no deben condicionarla ni manipularla conforme sus opiniones personales.

Este precedente trasciende el contexto colombiano e importa a toda la región latinoamericana, en donde con frecuencia el acceso efectivo para las mujeres a los servicios de salud sexual y reproductiva a los que tienen derecho, se ve obstaculizado por los mismos funcionarios llamados a garantizarlos y es prueba de la importancia del uso e impulso del litigio estratégico que cada vez con más frecuencia se verifica en la misma región.

El Tribunal al valorar el Estado Democrático de Derecho contemporáneo y asignarle una significación especial al marco legal y a su interpretación jurisprudencial, una vez más mantiene en el poder judicial colombiano un protagonismo notorio en las políticas públicas de salud. No obstante, con cada nuevo litigio reabre eventualmente la discusión de cómo puede comprometer a los tres poderes del Estado para mediar en la conflictividad judicial existente, a través de un adecuado dialogo propio del Estado Democrático de Derecho.

Por último vale precisar que en fecha 19/9/2012, el Procurador General de la Nación ha publicitado que emitió la Resolución 308 por la cual dicho órgano acató en un todo la sentencia, dejando sin efecto la Circular 029 de 2010 y, parcialmente (numeral 8) la 021 del 2011, comunicando la norma ${ }^{14}$.

\footnotetext{
${ }^{14}$ PROCURADURÍA GENERAL DE LA NACIÓN - Rep. de Colombia. Comunicado de Prensa Boletín 973, miércoles, 19 septiembre 2012. Disponible en: <http://www.procuraduria.gov.co>. Consultado el: 1 oct. 2013.
} 


\section{Referencias}

BENÍTEZ R., Vicente F. Legitimidad democrática y constitucional de las modificaciones implícitas de la Constitución por parte de la jurisprudencia de constitucional de Colombia. Universitas, n. 122, p. 303-334, 2011.

PROCURADURÍA GENERAL DE LA NACIÓN - Rep. de Colombia. Comunicado de Prensa Boletín 973, miércoles, 19 septiembre 2012. Disponible en: <http://www.procuraduria.gov. co>. Consultado el: 1 oct. 2013.

SALGADO ÁLVAREZ, Judith. Análisis de la sentencia de la Corte Constitucional de Colombia sobre la despenalización parcial del aborto. FORO Revista de Derecho, Quito, n. 9, 2008.

YAMIN, Alicia Ely; PARRA-VERA, Oscar; GIANELLA; Camila. Colombia: la protección judicial del derecho a la salud. ¿Una promesa difícil de cumplir? Con cita de Uprimny y García Villegas. In: YAMIN, Alicia Ely; GLOPPEN, Siri (coord.) La lucha por los derechos a de la salud. Ed. Siglo XXI, 2013, p. 127-157.

Claudia Viviana Madies - Magister en Sistemas de Salud y Seguridad Social, Universidad ISALUD; Magister en Bioética y Derecho, Universidad de Barcelona). Profesora Universitaria en Ciencias de la Salud y el Ambiente, Universidad ISALUD. Directora del Centro de estudio e Investigación en Derecho Sanitario y Bioderecho de la Universidad ISALUD. Abogada. Buenos Aires, Argentina. E-mail: madies.claudia@gmail.com.

Fabio Fidel Cantafio - Posgrado en Propiedad Intelectual, Facultad de Derecho y Ciencias Sociales, Universidad de Buenos Aires. Abogado. Buenos Aires, Argentina. 